\title{
Cardiovascular risk stratification in diabetic patients
}

\author{
Mario Petretta - Wanda Acampa · Giovanni Fiumara • \\ Alberto Cuocolo
}

Received: 30 May 2013/Accepted: 5 September 2013/Published online: 1 October 2013

(C) Italian Association of Nuclear Medicine and Molecular Imaging 2013

\begin{abstract}
Several studies, reporting that diabetes is associated with a marked increase in the risk of coronary artery disease $(\mathrm{CAD})$, introduced the concept that diabetes is $\mathrm{CAD}$ equivalent, and thereby provided a rationale for treating cardiovascular risk factors in diabetic patients as aggressively as in non-diabetic subjects with prior myocardial infarction. However, the concept of CAD risk equivalence in diabetes has been challenged by other studies. The classification of individuals with diabetes as having a risk level equivalent to that of individuals without diabetes who survived a cardiovascular event is an approach that fails to account for the fact that cardiovascular risk is not uniformly distributed, but follows a gradient from the lowest to the highest risk. Prediction models, based on numbers of risk factors, have been proposed for patients with diabetes. Most cardiovascular prediction models have been developed in general populations, including diabetes as a predictor, while a smaller number of studies have endeavored to construct CAD risk scores
\end{abstract}

\footnotetext{
M. Petretta

Department of Translational Medical Sciences, Federico II University, Naples, Italy

W. Acampa

National Research Council, Institute of Biostructure and Bioimaging, Naples, Italy

G. Fiumara

SDN Foundation, Institute of Diagnostic and Nuclear

Development, Naples, Italy

A. Cuocolo $(\square)$

Department of Advanced Biomedical Sciences, Federico II

University, Naples, Italy

e-mail: alberto.cuocolo@unina.it
}

primarily in diabetic patients. The detection of occult CAD is the objective of non-invasive of testing diabetic patients for risk stratification purposes. Among the non-invasive imaging modalities, stress myocardial perfusion singlephoton emission computed tomography has been widely used in diabetic patients. This review discusses the importance of using clinical prediction models in the diabetic population and the different challenges of non-invasive imaging for risk stratification, considering that the questions of when, how, and which diabetic patients should be studied are still open ones.

Keywords Diabetes mellitus - Myocardial perfusion imaging $\cdot$ Prognosis

\section{Introduction}

Diabetes is a group of metabolic diseases characterized by hyperglycemia resulting from defects in insulin secretion, insulin action, or both [1]. The chronic hyperglycemia of diabetes is associated with long-term damage of several organs, in particular the eyes, kidneys, nerves, heart, and blood vessels. The World Health Organization estimated that the global population of people with diabetes was 30 million in 1985. By 1995, this number had increased to 135 million and in 2005 it stood at 217 million. It is expected to rise to at least 366 million by the year 2030 [2]. Data from the 2011 National Diabetes Fact Sheet [3] report a total prevalence of diabetes of 25.8 million children and adults in the United States (8.3\% of the population) and a prevalence of pre-diabetes (a condition in which individuals have blood glucose or hemoglobin A1c levels that are higher than normal but not high enough to be classified as diabetes) of 79 million people. 
Notably, in 2010, 1.9 million new cases of diabetes were diagnosed in people aged 20 years and older in the United States. In 2007, the total costs of diabetes in the United States were estimated at $\$ 174$ billion. Type 2 diabetes mellitus is a disease characterized by insulin resistance and, usually, by relative (rather than absolute) insulin deficiency. Initially at least, but often throughout their lifetimes, individuals with type 2 diabetes do not need insulin treatment to survive. Most patients with this form of diabetes are obese and obesity itself causes some degree of insulin resistance. Diabetes is also associated with a high prevalence of hypertension. Indeed, in 2005-2008, $67 \%$ of adults aged 20 years or older with self-reported diabetes had blood pressure greater than or equal to $140 / 90 \mathrm{mmHg}$ or used prescription medications for hypertension [3]. Approximately $90-95 \%$ of diabetics have type 2 diabetes mellitus, but both type 1 and type 2 diabetes are associated with an increased risk of cardiovascular disease [4-6]. The prospective multinational Ischemia assessment with exercise imaging in asymptomatic diabetes study recently recruited participants at 12 sites in Asia, Africa and Latin America in order to compare the prevalence of silent ischemia in diabetes patients versus controls by means of stress myocardial perfusion single-photon emission computed tomography (MPS) in developing nations [7]. A higher proportion of the diabetes mellitus group had MPS abnormalities compared with controls (26 vs $14 \%$, $p<0.001)$. Of the participants with ischemia on MPS, $17 \%$ had ischemic signs on electrocardiography (ECG), whereas $10 \%$ of those without ischemia had an ischemic ECG. In a multivariable model, diabetes was independently associated with abnormal MPS $(p=0.004)$. Women were less likely to have ischemia on MPS than men (10 vs $30 \%$, $p<0.001)$ and concordance between ECG and MPS was much worse in women.

\section{Is diabetes CAD equivalent?}

Several epidemiological studies reported that diabetes is associated with a marked increase in the risk of coronary artery disease (CAD) [8-10]. In a Finnish population-based study, Haffner et al. [11] found that diabetic patients without prior myocardial infarction have as high a cardiac risk as non-diabetic patients with previous infarction. These data introduced the concept that diabetes is CAD equivalent, providing a rationale for treating cardiovascular risk factors in diabetic patients as aggressively as in nondiabetic patients with prior myocardial infarction [12]. However, in Haffner's study [11] the majority of the patients were hypertensive, most of the patients with diabetes had uncontrolled glycemia, and these patients' lipids were not at target as per current standards. A meta-analysis of 37 prospective cohort studies [13] confirmed the excess risk of fatal CAD associated with diabetes; however, the relative risk for fatal $\mathrm{CAD}$ associated with diabetes was $50 \%$ higher in women than in men and the greater excess coronary risk was explained by more adverse cardiovascular risk profiles among women with diabetes, as well as by possible disparities in treatment that favor men. The concept of CAD risk equivalence in diabetes has been challenged by numerous studies [14-16]. It has also been suggested that CAD risk equivalence in diabetics depends more on concomitant risk factors for $\mathrm{CAD}$ than on diabetic status alone [17]. A meta-analysis involving in excess of 45,000 patients did not support the hypothesis that diabetes is CAD equivalent [18]. Furthermore, the Detection of Silent Myocardial Ischemia in Asymptomatic Diabetic Subjects (DIAD) study showed that cardiac event rates in diabetic subjects are low [19]. Therefore, other variables, rather than the diabetic state per se, seem to determine the future cardiac event rate suggesting the need for a change to the paradigm of diabetes as a CAD risk equivalent [20].

Opposite results were reported by a meta-analysis of individual patient records that included data from 698,782 subjects without initial vascular disease (52,765 non-fatal or fatal vascular outcomes) from 102 prospective studies in the emerging risk factors collaboration [21]. The authors combined within-study regressions that were adjusted for age, sex, smoking, systolic blood pressure, and body mass index to calculate hazard ratios for vascular disease. They found that diabetes confers an approximately twofold excess risk for a wide range of vascular diseases, independently of other conventional risk factors. Interestingly, in this meta-analysis, in people without diabetes, fasting blood glucose concentration was modestly and non-linearly associated with the risk of vascular disease. This latter observation supports the results of a previous study demonstrating an elevated risk of cardiovascular disease prior to clinical diagnosis of diabetes in 117,629 female nurses, free of diagnosed CAD at baseline and followed for 20 years [22]. These data indicate a substantially elevated risk of CAD before clinical diagnosis of type 2 diabetes in women, suggesting that aggressive management of cardiovascular risk factors is warranted in individuals at increased risk of diabetes.

The adverse cardiac prognosis of diabetic patients might also be related to the systolic dysfunction observed in this population, frequently independently of the presence and extent of CAD [23]. In addition, abnormalities of left ventricular (LV) diastolic function have been observed in $27-70 \%$ of asymptomatic diabetic patients probably due to fibrosis and increased LV mass [24, 25]. Recently, diabetes mellitus has been recognized as an especially strong risk factor for the development of heart failure with preserved ejection fraction, particularly in women [26]. The 
investigators of the Raloxifene use for the heart (RUTH) trial evaluated a very large cohort of women and followed them up for cardiovascular events and all-cause mortality to evaluate independent cardiovascular risk of diabetes specific to women [27]. This study demonstrated a high trend for all-cause mortality in women with diabetes but cardiovascular events were $39 \%$ lower in those with diabetes $(p<0.0001)$ than in those without. This suggests that diabetes may be affecting more than the coronaries, and that the risk in diabetic women is multifactorial, but diabetes alone does not impart, in diabetic women, a cardiovascular risk equivalent to that of women with known CAD. These findings are supported by the results of the multi-ethnic study of atherosclerosis (MESA) [28], which demonstrated that in people with diabetes, without further stratification, the annual rate of cardiovascular events does not reach $2 \%$.

Interestingly, in spite of potent pro-inflammatory, prooxidant and pro-thrombotic stimuli operating in type 2 diabetes, diabetic patients exhibit substantially more severe coronary atherosclerosis than non-diabetic patients at the time of a first acute coronary event. Better collateral development towards the culprit vessel, a predominantly calcified plaque phenotype and, probably, as yet unknown protective factors operating in diabetic patients may explain these intriguing paradoxical findings [29]. In addition, diabetic patients might have limited levels of warning signs [30]. Therefore, when diabetic patients undergo coronary angiography for the first time, they might show more extensive coronary atherosclerosis and a better collateral circulation towards the culprit vessel when compared with non-diabetic patients [31]. Unrecognized non-Q-wave myocardial infarction is also frequent in diabetic patients and has prognostic implications [32, 33]. Davis et al. [34] examined data from the 5,102 patients in the 30-year UK prospective diabetes study (UKPDS) and found that about one in six patients with newly diagnosed type 2 diabetes mellitus had evidence of silent myocardial infarction, which was independently associated with an increased risk of fatal infarction and all-cause mortality.

\section{Clinical prediction models in diabetes}

The classification of individuals with diabetes as having a risk level equivalent to that of individuals without diabetes who survived a cardiovascular event is an approach that fails to account for the fact that cardiovascular risk is not uniformly distributed, but follows a gradient from the lowest to the highest risk. Several prediction models, based on numbers of risk factors, have been proposed for patients with type 2 diabetes [35-37]. Most cardiovascular prediction models have been developed in general populations including diabetes as a predictor, while a smaller number of studies have endeavored to construct CAD risk scores primarily in individuals with diabetes. Of these latter, only two prediction models were developed in patients with newly diagnosed diabetes [38, 39], while the others concerned subjects with varying duration of diagnosed diabetes. Numerous scores are now available, all of which have strengths and limitations and none of which is perfect. However, a systematic review of these tools is beyond the scope of this paper.

The DIAD study [40] evaluated the baseline cardiovascular risk of 1,123 participants using four established methods: the Framingham score, the UKPDS risk engine, the criteria of the French-Speaking Association for the study of diabetes and metabolic diseases, and the presence or absence of metabolic syndrome. Using various riskstratification approaches, 53-75\% of participants were defined as having intermediate or high cardiovascular risk. The prevalence of inducible ischemia on screening in these individuals ranged from 21 to $24 \%$, and was therefore similar to that of lower-risk participants (19-23\%). The annual cardiac event rate was $<1 \%$ in all risk groups, except for the high-risk UKPDS group ( $>2 \%$ per year). Thus, a substantial portion of the DIAD population was defined as having intermediate/high baseline cardiovascular risk, but their annual cardiac event rate was low. Different methods for quantifying the improvement in risk estimation when an additional test is added to a standard risk prediction model have recently been introduced [41]. Net reclassification improvement has been adopted in diabetic patients with suspected or known CAD to evaluate the extent to which adding MPS imaging data to a model based on traditional risk factors and ECG stress test data correctly reclassifies the risk of subsequent cardiac events during a long-term follow-up (Fig. 1). As existing cardiovascular risk prediction equations perform non-optimally [42], there is a continuing need to develop new equations to accurately predict, in various settings, cardiovascular risk in different populations with diabetes. In addition, robust evidence on the impact of the use of risk prediction models on patient outcomes such as adherence to medications, patient understanding or improvements in harder outcomes is still lacking. Until such evidence is available, the use of risk prediction models in routine clinical practice will continue to carry uncertainty and a risk of misclassification.

\section{Testing asymptomatic diabetic patients}

Risk stratification is widely used in the prognostic assessment of patients with a variety of clinical disorders on the unquestioned assumption that the intensity of treatment should be proportionate to the risk of an adverse event over 
Diabetic patients with suspected or known CAD ( $n=822)$
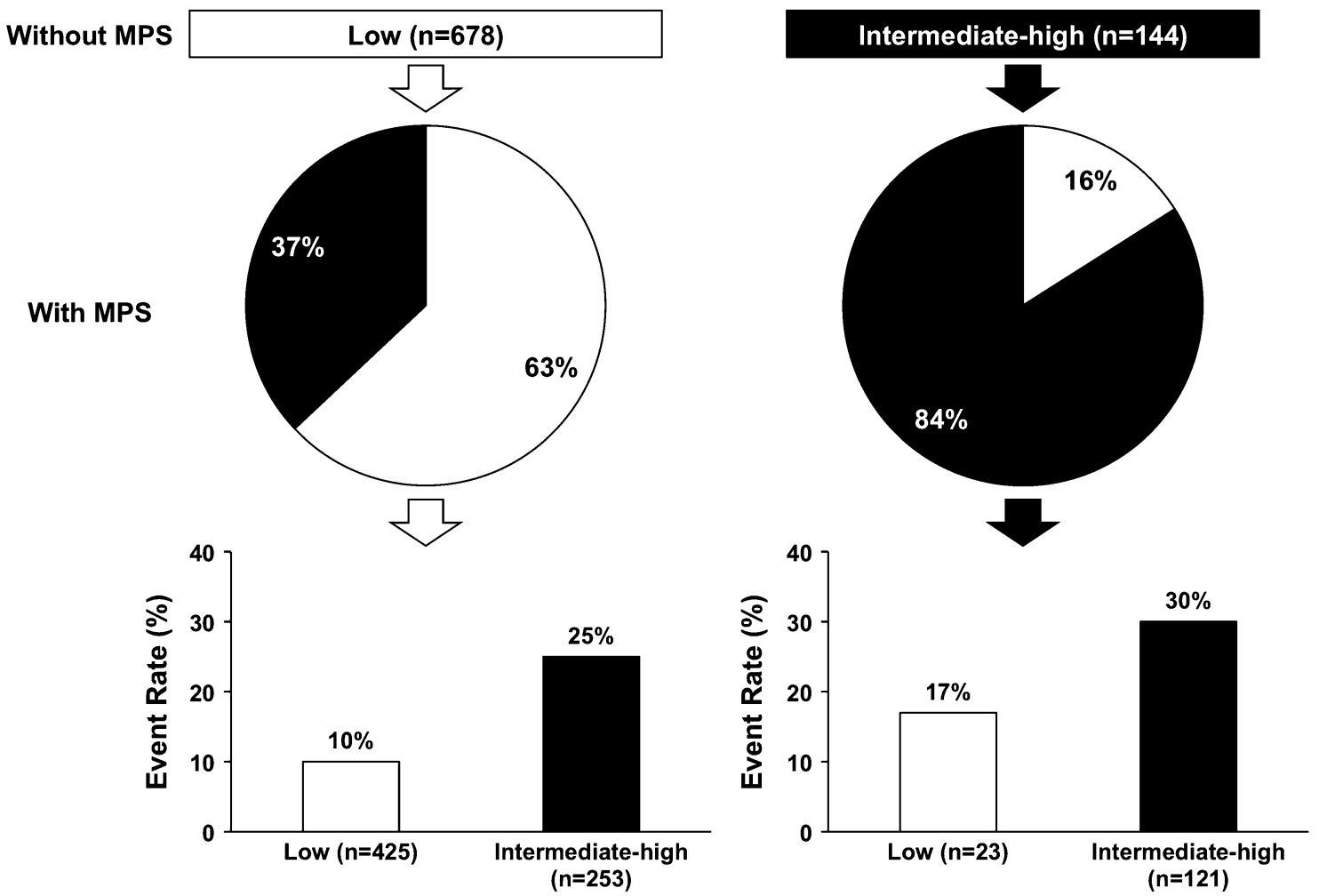

Fig. 1 Risk reclassification by addition of stress MPS data to a model containing clinical risk factors and ECG stress test data. The horizontal bars at the top indicate the distribution of risk $[<3 \% /$ year (white) and $\geq 3 \% / y e a r$ (black)] of coronary heart disease events (cardiac death, non-fatal myocardial infarction, and unstable angina requiring coronary revascularization) as estimated by a model containing clinical risk factors and ECG stress test data. The pie

some finite period of time. Furthermore, while most studies published since that of Haffner et al. [11] indicate that people with diabetes are not quite equivalent to those people with known $\mathrm{CAD}$, there is, nevertheless, large consensus that the presence of diabetes carries an elevated cardiovascular risk. Thus, it remains unclear whether all subjects with diabetes should be treated as CAD risk equivalents, even though many do not achieve that risk status [43], or whether they should instead be further stratified in order to better align intensity of therapy with levels of cardiovascular risk [44-46]. Major society guidelines and position statements have made the following recommendations about testing for asymptomatic CAD in diabetic patients.

1. The 2002 ACC/AHA guidelines update for exercise testing stated that asymptomatic diabetic patients have an increased likelihood of cardiovascular disease if they have at least one of the following factors: age older than 35 years, type 2 diabetes duration longer than 10 years, any additional atherosclerotic risk factor graphs show the proportions of patients in each pre-MPS category reassigned to each risk category after the addition of stress MPS data to the risk model. The vertical bar charts at the bottom show the cumulative event rates of coronary heart disease events in each of the post-MPS risk categories during a follow-up of $58 \pm 11$ months (data from Acampa et al. [41])

for CAD, presence of microvascular disease, peripheral vascular disease or autonomic neuropathy. The guidelines recommend exercise testing in the event that an individual meeting the above criteria is planning to begin a moderate- to high-intensity exercise (class IIa; level of evidence C) [47].

2. The 2009 appropriate use criteria for cardiac radionuclide imaging, published by the American College of Cardiology and endorsed by many other professional societies [48], considered the use of radionuclide imaging appropriate for asymptomatic patients with diabetes mellitus (patients $>40$ years old) and other coronary risk equivalents. An appropriate imaging study is one in which, for a specific indication, the expected incremental information, combined with the clinical judgment, exceeds the expected negative consequences (including the risks of the procedure radiation) by a sufficiently wide margin for the procedure to be considered, generally, acceptable care and a reasonable approach for that indication [49]. 
3. The $2010 \mathrm{ACCF} / \mathrm{AHA}$ guidelines for the assessment of cardiovascular risk in asymptomatic adults [50] recommend measurement of coronary artery calcium (CAC) for cardiovascular risk assessment in asymptomatic adults with diabetes aged 40 years or older (class IIa recommendation, level of evidence B). The authors acknowledge that there is no evidence suggesting that this imaging test is useful in motivating patients to adhere to primary prevention measures. The same guidelines weakly recommend considering stress MPS for advanced cardiovascular risk assessment in asymptomatic adults with diabetes or in patients who have a calcium score of 400 or greater (class IIb recommendation, level of evidence $\mathrm{C}$ ).

4. A 2011 position statement from the Working Group on nuclear cardiology and cardiac computed tomography (CT) of the European Society of Cardiology [51] states that in unselected, asymptomatic diabetic individuals stress MPS is not recommended (class of recommendation III). However, the presence of coronary calcium detected by cardiac CT preselects diabetic individuals with increased likelihood of myocardial ischemia on MPS. Asymptomatic type 2 diabetic patients without known CAD should thus be considered for coronary calcium imaging, which should be followed by MPS in those with significant coronary calcium, in order to identify subjects with a moderate to severe extent of ischemia who are likely to benefit from invasive evaluation and revascularization (class of recommendation IIa).

5. The American Heart Association guidelines for women [52] state that low-density lipoprotein cholesterol-lowering drug therapy is recommended simultaneously with lifestyle therapy to achieve a low-density lipoprotein cholesterol $>100 \mathrm{mg} / \mathrm{dL}$ in women with CAD (class I; level of evidence A) and is also indicated in women with other atherosclerotic cardiovascular disease or diabetes or a 10 -year absolute risk $>20 \%$ (class I; level of evidence B). The implications of the guidelines are that diabetes imparts a 10-year absolute risk of $>20 \%$ also in women.

6. In a recent 2013 position statement on standards of medical care in diabetes [53], the American Diabetes Association (ADA) does not recommend screening for CAD in asymptomatic patients because it does not improve outcomes as long as cardiovascular risk factors are treated (level of evidence A). The guidelines acknowledge that newer, non-invasive CT modalities can identify asymptomatic diabetic patients with a higher CAD burden and a higher risk of future cardiac events. However, they consider that the role of these tests beyond risk stratification is unclear, with a controversial cost-benefit-risk balance.
The detection of occult $\mathrm{CAD}$, in order to allow the initiation of appropriate therapy at a time point when the disease process is more easily modifiable, is the objective of non-invasive testing of asymptomatic diabetic patients for risk stratification purposes. This strategy is expected to lead to declines in cardiac morbidity and mortality. In this context certain important questions are still to be addressed, such as the potential of coronary revascularization to reduce cardiac events in asymptomatic diabetic patients; the yield of non-invasive testing in identifying, reliably, a considerable proportion of those patients likely to benefit from this type of intervention in a cost-effective manner; and the questions of who, when and how to test $[54,55]$.

\section{Non-invasive imaging for detecting subclinical coronary atherosclerosis in diabetes}

Different non-invasive cardiac testing modalities for the assessment of diabetic patients can allow direct visualization of atherosclerotic involvement of the coronary artery wall and lumen (multislice or electron beam CT and cardiac magnetic resonance) or determination of the hemodynamic consequences of coronary artery lesions (exercise ECG, stress echocardiography, and stress MPS).

\section{Radionuclide imaging}

Among these non-invasive imaging modalities, stress MPS has been widely used in asymptomatic diabetic patients with unrecognized CAD. In many diabetic subjects exercise capacity is impaired and pharmacological stress (dipyridamole or adenosine) may be the only option for testing. Importantly, gated MPS may improve the clinical efficacy of stress testing, allowing the simultaneous assessment of myocardial perfusion and LV function [56, 57] and attenuation correction [58]. Studies assessing stress-induced ischemia in asymptomatic diabetic patients with unrecognized CAD show a wide range of prevalence: from as low as $4 \%$ [59] to $62 \%$ [60]. Differences in study design (retrospective vs prospective), study population characteristics, and stress testing methodology may explain these differences in prevalence. Also the diagnostic performance of MPS, based on coronary angiography as the gold standard, varies widely in asymptomatic diabetic subjects. Senior et al. [61] reported a sensitivity of $4 \%$ and a specificity of $93 \%$, while Rajagopalan et al. [62] reported, respectively, values of 92 and $32 \%$.

In addition to documenting the presence of ischemia, myocardial perfusion imaging provides information on the potential risk of future cardiac events. Retrospective [6264] and prospective [19, 65] studies have evaluated the incidence of hard events (cardiac death and myocardial 
infarction) in asymptomatic diabetic patients according to cardiac nuclear stress testing results. In these investigations, the annual event rate ranged from $2.4 \%$ [19] to $5.8 \%$ [64] in subjects with abnormal MPS and from $0.4 \%$ [19] to $2.1 \%$ [65] in those with normal MPS. Similar results were observed in studies including soft events (angina, revascularization, heart failure, and stroke) together with hard events as endpoints [66-70]. Few data are available on the comparative ability of stress MPS risk markers using varied iterative and risk classification approaches in asymptomatic diabetic patients. Acampa et al. [71] recently compared analytical approaches to estimate the added value of MPS variables in estimating CAD outcomes in 436 asymptomatic diabetic patients (Fig. 2). On multivariable analysis, post-stress LV ejection fraction and stress MPS ischemia were independent predictors of CAD death or myocardial infarction (both $p<0.01)$. The net reclassification improvement obtained by adding MPS results to a model including pre-test CAD likelihood was 0.25 (95\% confidence interval 0.06-0.44; $p<0.01)$. Parametric survival analysis showed the highest probability of CAD death or myocardial infarction and the greatest risk acceleration in time in patients with stress MPS ischemia and post-stress LV ejection fraction $\leq 45 \%$ (Fig. 3). Bourque et al. [72] evaluated the prevalence of ischemia, subsequent cardiac events, and impact of gender, stress type, and symptom status in a cohort of 575 stable diabetic outpatients referred for MPS. These patients had low rates of significant ischemia and early revascularization; an initially low cardiac event rate increased after 2 years. Known CAD, pharmacological stress, and MPS ischemia emerged as independent predictors of cardiac death/non-fatal myocardial infarction. Nearly one-third of those with events had a normal MPS, indicating a need for improved risk stratification.

\section{Calcium score and CT angiography}

Newer non-invasive CAD screening methods, such as measurement of CAC and CT angiography have grown in popularity. These tests infer the presence of coronary atherosclerosis by measuring the amount of calcium in coronary arteries and, in some circumstances, by directly visualizing luminal stenoses. Diabetic patients had a significantly higher prevalence of plaques in every anatomical subset, with higher coronary atherosclerotic burden indexes and more mid-to-distal localization as compared to nondiabetics [73]. Although asymptomatic diabetic patients found to have a higher coronary disease burden have more future cardiac events, the role of these tests for risk stratification and for patient management is not clear [74].

Agarwal et al. [75] found that CAC is an independent predictor of mortality in diabetes, and that participants with
CAC 0-9 were at lower risk (0.9 \% annual mortality). The risk of mortality increased with increasing levels of CAC, plateauing at approximately $\mathrm{CAC} \geq 1,000$ (2.7\% annual mortality). Moreover, in a subsequent analysis, the same authors [76] found that CAC predicts cardiac mortality and meaningfully reclassifies diabetic subjects, suggesting its clinical utility as a risk stratification tool in a population already at increased cardiovascular disease risk. However, the routine use of calcium score and CT angiography leads to radiation exposure and may also result in unnecessary invasive testing, such as coronary angiography and revascularization procedures [53].

The prediction of future cardiac events, such as myocardial infarction, is another area of uncertainty. In fact, the detection of coronary atherosclerosis is not always predictive of infarction, and a large proportion of patients with suspected CAD who are referred for coronary CT angiography have coronary atherosclerotic lesions that do not cause significant anatomical luminal obstruction [77, 78]. Nevertheless, these non-obstructive coronary artery lesions provide incremental prognostic information over the presence of obstructive lesions and clinical variables [74, 77, 78]. High-risk plaques on CT angiography are commonly considered to be those that are non-calcified or mixed as opposed to calcified ones. Moreover, coronary arterial plaques are typically reviewed by CT angiography in either axial or multiplanar reformatted planes, as well as in curved multiplanar reformats allowing the definition of the bifurcation angle. Interestingly, a wide bifurcation angle predicted the presence of high-risk and non-calcified plaques in the proximal segment [79]. Local hemodynamic factors, in particular low endothelial shear stress, play a major role in the regional localization of atherosclerosis and promote the development of plaques with high-risk features, such as positive remodeling, a large lipid core and inflammation. However, the management of such lesions remains inadequately defined and there is a need for markers that could identify atherosclerotic plaques associated with high risk of events such as myocardial infarction [80, 81].

The implications of a negative CAC on patient management are also debated. The ADA [53] recommended that cardiovascular risk factors should be assessed at least annually in all patients with diabetes. Abnormal risk factors should be appropriately treated and patients at increased CAD risk should receive aspirin and a statin, and angiotensin-converting enzyme inhibitor or angiotensin-receptor blocker therapy if hypertensive, unless there are contraindications to a particular drug class. However, primary prevention trials with statins are not definitive [82]. Data suggest that low-risk patients do not benefit much from cholesterol-lowering medications, as the number of cardiovascular events (if any) 
Asymptomatic diabetic patients $(n=436)$

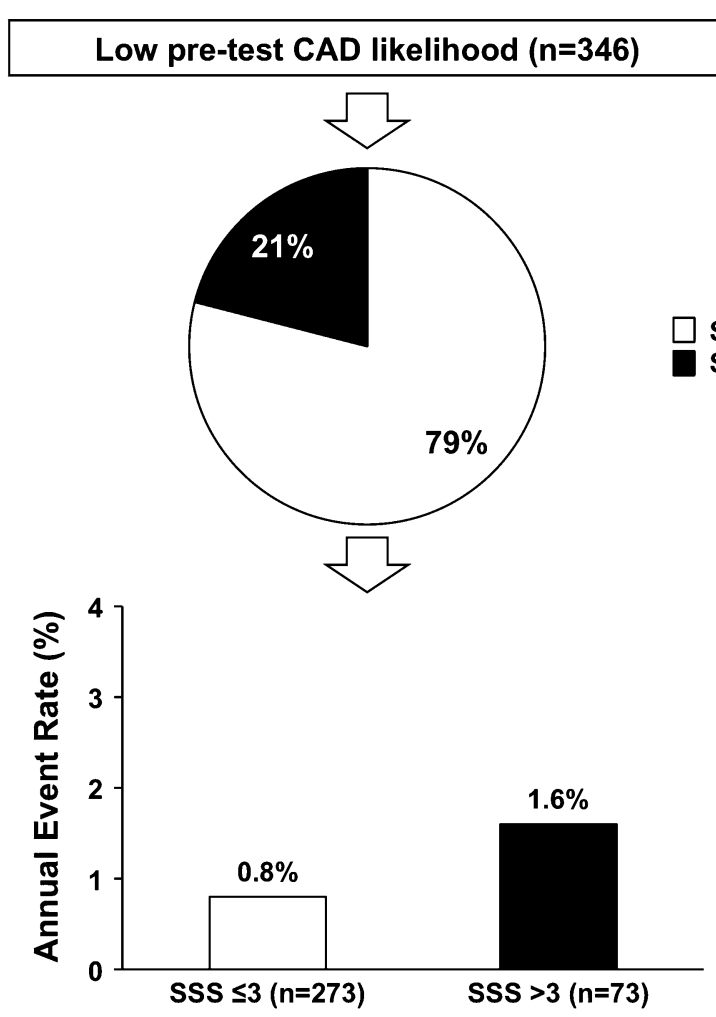

Fig. 2 Annualized cardiac event rate in asymptomatic diabetic patients stratified according to the pre-test likelihood of CAD and MPS results. The horizontal bars at the top indicate the distribution of patients across low $(n=346)$ and intermediate-high $(n=90)$ pre-test CAD likelihood categories. The pie graphs show the proportions of

prevented by these drugs is too small, and the number needed to treat too high, rendering these drugs probably not indicated for primary prevention in zero CAC patients unless cholesterol levels are very high [83]. It should be noted that a screening strategy to prevent atherosclerotic events in asymptomatic diabetic patients has been questioned. Diamond et al. [43] analyzed the expected cost and benefit associated with a conditional test-treatment strategy (testing followed by statin treatment in positive test responders) in comparison to an unconditional treatment strategy (no testing and statin treatment in all). This analysis shows that unconditional treatment should be the dominant strategy, costing less and preventing more atherosclerotic events annually on a national USA basis. As regards aspirin, the ADA recommend aspirin in primary prevention only if the patient has a 10-year risk for cardiovascular events greater than $10 \%$ [53], which is probably not the case for any subgroup of zero CAC patients [84]. Of course, healthy lifestyle changes such as exercise, better eating habits, and smoking cessation should be encouraged regardless of the calcium score.
Intermediate pre-test CAD likelihood $(n=90)$

SSS $\leq 3$

SSS $>3$
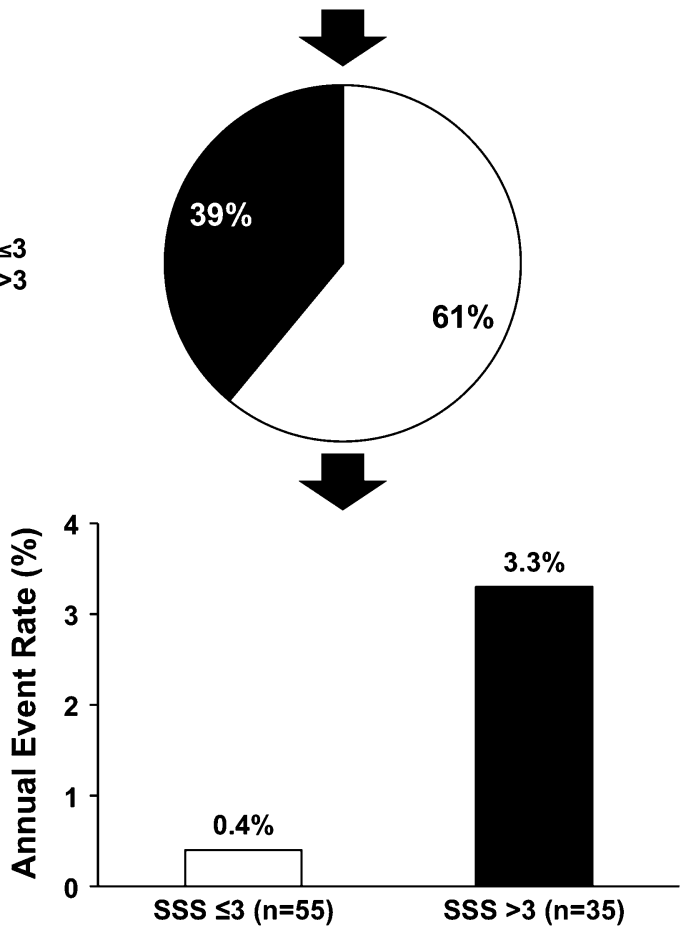

patients in each likelihood category with normal (white) or abnormal (black) stress MPS results. The vertical bar charts at the bottom represent the annualized rates of cardiac death or non-fatal myocardial infarction in each group (data from Acampa et al. [70]). SSS: summed stress score

\section{Which diabetic patients should be referred for MPS?}

Several studies have used different algorithms to identify diabetic patients who should or should not be referred for MPS. These algorithms have been based on numbers of traditional or emerging cardiovascular risk factors, the presence or absence of endothelium-dependent vasodilatation, the results of exercise ECG, or CAC score measurements [30, 85-89]. In particular, the presence of CAC is associated with a subsequent risk of cardiac events, with 1-99 Agatston units indicating low risk; 100-400 moderate risk; and $>400$ high risk [90]. Anand et al. [91] followed a two-stage strategy (calcium score through multislice CT scan, followed by gated MPS for those who scored $>100$ Agatston units and for a random sample of those with scores of $\leq 100$ ) and found that the calcium score was better than established risk factors at predicting silent ischemia and cardiac events in persons with diabetes. However, this approach could miss non-calcified soft plaques as well the presence of microvascular angina. Missing non-calcified soft plaques and microvascular angina, and thus excluding MPS, would be a drawback of this strategy. 
Fig. 3 Estimated time from index MPS to reach a $3 \%$ risk of cardiac death or non-fatal myocardial infarction in asymptomatic diabetic patients at low (a) or intermediate-high (b) pre-test CAD likelihood with normal or abnormal stress MPS and with or without poststress left ventricular ejection fraction $(\mathrm{LVEF}) \leq 45$. (Data from Acampa et al. [70]). SSS summed stress score
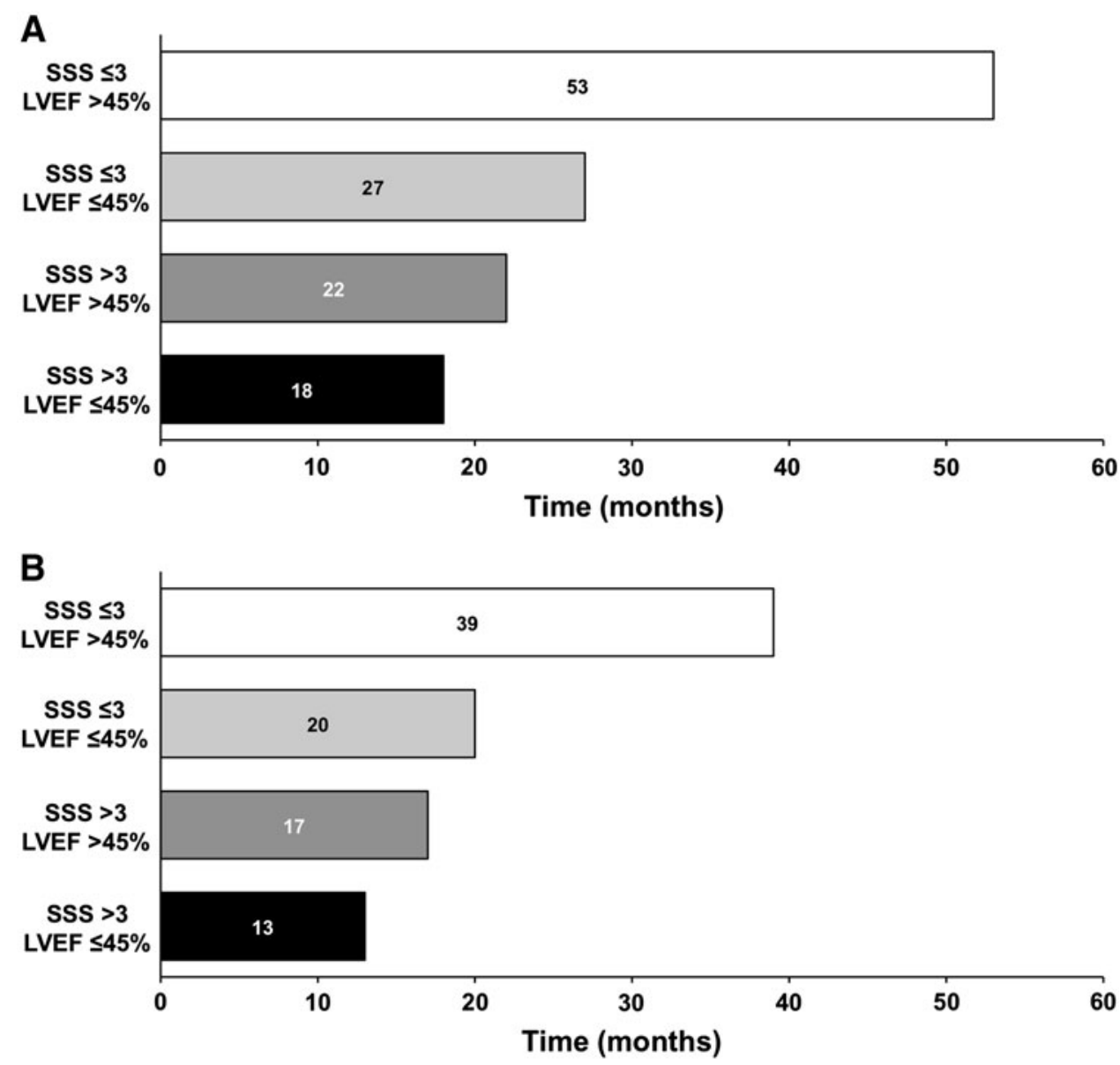

The presence of peripheral vascular disease, carotid disease, retinopathy, endothelial dysfunction, peripheral neuropathy, autonomic dysfunction, a family history of CAD, microalbuminuria or renal insufficiency confers additional risk and suggests the need for testing to detect ischemia, even if the calcium score is $<100$ [92-95]. However, no generally accepted algorithm has been established.

\section{When should diabetic patients be retested?}

The questions of when, how, and which asymptomatic diabetic patients should be screened are not the only open issues; indeed, the warranty period of a normal imaging study in these subjects is another issue that remains to be defined [96]. Giri et al. [97] evaluated the use of stress MPS for risk stratification of patients with symptoms suggestive of CAD who had been referred to the nuclear cardiology stress laboratory for cardiac evaluation. This multicenter study involved 4,755 patients (929 diabetic) patients followed for 2.5 years. The diabetic patients had a significantly higher cardiac event rate (death and myocardial infarction) compared with the non-diabetic cohort. However, after adjustment for clinical variables and MPS results, cardiac survival was comparable, indicating that MPS prognostic categorization supersedes the adverse predictive value of diabetes mellitus as a univariable parameter. Of substantial clinical interest was the observation that, after the index study, patients with diabetes mellitus and normal stress MPS images had a significantly higher 2-year cardiac event rate than did the patients without diabetes. This prognostic finding is in marked contrast to the experience in the non-diabetic population, in whom the association of normal MPS and excellent outcome has been well demonstrated [98, 99]. Thus, retesting of diabetic patients with normal studies should occur earlier than in a non-diabetic population and a follow-up MPS after 2 years might be reasonable. However, the database analysis of Giri et al. [97] did not include asymptomatic diabetic patients, thus more data are needed to establish, definitively, the follow-up interval necessary in these subjects.

The interval for retesting patients with zero CAC is still debated and it has been suggested that it should not be less than 4-5 years [100]. A recent study evaluated differences in CAC progression rates, the effect of statin therapy, and all-cause mortality in subjects with and without diabetes [101]. CAC progression was greater and event-free 
survival lower in patients with diabetes compared to controls, the latter in proportion to the extent of the CAC progression. These results suggest that $\mathrm{CAC}$ progression is an independent predictor of all-cause mortality in patients with diabetes and that statins may improve survival in patients with and in those without diabetes and both with and without CAC progression. These findings might have an impact on physician decision-making, performance, and reimbursement policy, and will help to guide future research.

\section{Assessment of LV function by echocardiography}

Echocardiography may be useful for the diagnosis of diabetic heart disease, which requires the demonstration of myocardial dysfunction in the absence of other causes, such as coronary artery stenosis or hypertension. Therefore, in diabetic patients the presence of LV dysfunction without other overt causes is suggestive for the diagnosis of diabetic cardiomyopathy. With the introduction of tissue Doppler imaging, quantification of longitudinal myocardial velocities has simplified the interpretation of $\mathrm{LV}$ diastolic function. Myocardial strain and strain rate imaging allows quantification of active myocardial deformation that is independent of translational motion and tethering artifacts [102]. In addition, two-dimensional speckle tracking has been used to evaluate LV diastolic function. These new echocardiographic approaches are more sensitive in identifying subclinical LV systolic and diastolic dysfunctions. $\mathrm{Ng}$ et al. [103] used two-dimensional speckle tracking echocardiography to compare diabetic patients with normal healthy controls. Even though all the diabetic patients had good glycemic control and were asymptomatic without evidence of diabetic complications, CAD or hypertension, two-dimensional speckle tracking was able to identify significant subclinical LV dysfunction in this group compared with the controls. These authors also demonstrated reduced longitudinal strain and strain rate but preserved circumferential and radial strain and strain rates in asymptomatic diabetic patients [103]. These findings suggest that cardiac dysfunction in early diabetic cardiomyopathy may start in the subendocardium, and the maintenance of circumferential and radial functions accounts for the initial preservation of LV volumes and ejection fraction.

\section{Impact of revascularization on outcome in diabetic patients with silent myocardial ischemia}

Overall, the accumulated evidence seems to indicate that stress MPS is an independent predictor of outcome in diabetes, and can add important prognostic information to that provided by standard risk factor assessment alone. However, it remains to be established whether it may guide treatment planning of asymptomatic diabetic patients better than current management recommendations. Hachamovitch et al. [104] in a large retrospective study of 10,627 patients followed up for a mean of $1.9 \pm 0.6$ years found, in patients with small amounts of inducible ischemia (5-10\% ischemic myocardium), a marginal survival advantage for medical therapy in women and no difference between therapies in men. Small survival advantages for revascularization over medical therapy in both men and women were noted in patients with moderate amounts of inducible ischemia (10-20\% myocardium ischemic), more marked in diabetic patients. In patients with large amounts of inducible ischemia ( $>20 \%$ myocardium ischemic), the survival benefit for revascularization increased more in women, such that it was more than twofold greater in women compared with men, a difference again more marked in diabetic patients. However, the propensity score adjusting for non-randomized therapy assignment identified inducible ischemia and angina symptoms as the best predictors of referral for early revascularization; moreover, data of asymptomatic diabetic patients could not be extrapolated from the presented data.

Data on CAD screening of asymptomatic diabetic patients from randomized trials are very limited. In the Milan study on atherosclerosis and diabetes (MiSAD), asymptomatic diabetic subjects with positive stress imaging results ended up experiencing a smaller number of major events than those with negative results over a fiveyear follow-up period, a finding attributed to therapeutic interventions and, in some instances, revascularization in higher risk patients identified through screening [66]. The same research team went on to show, in a small randomized study, that revascularization in asymptomatic diabetic patients who had positive scan results led to a much lower cardiac event rate after a mean follow-up period of 53.5 months, compared with the results in patients not submitted to screening [105]. Other investigators found similar and relatively low cardiac event rates between lowrisk asymptomatic diabetic subjects receiving usual care and high-risk asymptomatic diabetic patients receiving a myocardial ischemia-guided therapy, including revascularization in more than half of them [106]. A favorable outcome of revascularization in asymptomatic diabetic patients with extensive MPS defects was also observed in a retrospective database analysis [107]. This study group consisted of 826 asymptomatic diabetics without known CAD who had abnormal myocardial perfusion during stress MPS. Although coronary artery bypass graft was associated with better survival, mortality remained high (3\% per year). There was no survival advantage by treatment for 
patients with less severe MPS abnormalities. However, it is not clear whether the patients in the above studies had been receiving standard-of-care treatment for cardiovascular risk factors.

In a small study of asymptomatic type 2 diabetic patients, the prevalence of silent myocardial ischemia at stress MPS was low (16\%), $94 \%$ of patients had no detected CAD, and the cardiovascular event rate was less than $2 \%$ at a two-year follow-up [70]. Long-term intensive cardiovascular risk factor therapy and tight glycemia control were associated with low prevalence of silent myocardial ischemia and detected $\mathrm{CAD}$, and a very low cardiovascular event rate when revascularization of significant $\mathrm{CAD}$ at coronary angiography was added to the optimal medical therapy. The low rate of revascularization in this study underlines the importance of the contribution that intensive risk-factor treatment can make in the achievement of a good prognosis for these patients. In agreement with this hypothesis, the majority of patients enrolled in the DIAD study demonstrated resolution of ischemia upon repeat stress imaging after 3 years and this was attributed to more systematic treatment of cardiovascular risk factors [108]. Moreover, under extensive risk factor modification, the DIAD study found that both inducible ischemia and cardiac event rate were low, and that the use of MPS screening had no detectable effect on cardiac event rate [19]. The cumulative cardiac event rate was $2.9 \%$ over a mean follow-up of 4.8 years for an average rate of $0.6 \%$ per year. In the action to control cardiovascular risk in diabetes (ACCORD) trial [109], the subgroup of patients with diabetes without previous cardiovascular events, showed a slightly higher cardiac event rate $(1.4 \%$ per year), but this latter study included a selection of older patients with specific additional risk factors for cardiovascular disease. It is therefore conceivable that the DIAD results may not apply in certain higher risk asymptomatic diabetic subjects (e.g. those with abnormal ECG, or prior positive stress testing, or $>75$ years old). Moreover, ACCORD was not designed to assess the effect of revascularization and since relatively few participants underwent this type of intervention, it may not have fully prevented events. The multicenter Bypass Angioplasty Revascularization Investigation 2 Diabetes (BARI 2D) trial [110] randomized 2,368 patients with both type 2 diabetes and stable CAD (defined as $\geq 50 \%$ stenosis of a major epicardial coronary artery associated with a positive stress test or $\geq 70 \%$ stenosis of a major epicardial coronary artery and classic angina) to receive prompt revascularization with intensive medical therapy or intensive medical therapy alone. Over a follow-up period of 5.3 years, no significant difference in death or serious adverse cardiovascular events was observed between the two groups [110]. Only in patients with extensive CAD or impaired LV function did a strategy of prompt coronary artery bypass grafting significantly reduce the rate of a composite endpoint of death/myocardial infarction/stroke, but no difference in mortality was noted and treatment group differences were not significant in other clinicalangiographic risk groups within the coronary artery bypass graft surgery stratum, or in any subgroups within the percutaneous coronary intervention stratum [111]. It must be noted that during 5 years of follow-up in the BARI 2D study, $42 \%$ of patients randomized to optimal medical treatment showed changes in the clinical course that called for later revascularization. Moreover, many of the diabetic patients enrolled in BARI 2D had classical stable (51\%) or unstable $(9.5 \%)$ angina symptoms and the majority of them had known CAD, therefore results on asymptomatic patients are not available from this trial.

\section{Conclusions}

Non-invasive cardiac testing modalities may allow direct visualization of atherosclerotic involvement of the coronary artery wall and lumen (cardiac CT) or make it possible to determine the hemodynamic consequences of coronary artery lesions (functional stress perfusion imaging). Among these modalities, stress MPS has been widely used in diabetic patients with unrecognized CAD showing a wide range of prevalence of stress-induced ischemia, ranging from as low as 4-62\%. Retrospective and prospective studies evaluating the incidence of hard cardiac events in diabetic patients according to stress MPS results indicated an annual event rate ranging from 2.4 to $5.8 \%$ in subjects with abnormal and from 0.4 to $2.1 \%$ in those with normal myocardial perfusion. To identify the presence of CAD in diabetic patients without clear symptoms, a risk factorbased approach to the initial diagnostic evaluation and subsequent follow-up has intuitive appeal. However, as existing cardiovascular risk prediction equations perform non-optimally, there is a continuing need to develop new equations to accurately predict cardiovascular risk in different populations with diabetes. However, robust evidence on the impact of the use of risk prediction models on patient outcomes is still lacking and the ultimate costbenefit-risk balance of the different imaging modalities in asymptomatic patients remains controversial, particularly in the modern setting of aggressive cardiovascular risk factor control.

Conflict of interest M. Petretta, W. Acampa, G. Fiumara, A. Cuocolo declare no conflict of interest.

Human and Animal Studies This article does not contain any studies with human or animal subjects performed by any of the authors. 


\section{References}

1. American Diabetes Association (2013) Diagnosis and classification of diabetes mellitus. Diabetes Care 36(Suppl 1):S67-S74

2. Wild S, Roglic G, Green A, Sicree R, King H (2004) Global prevalence of diabetes: estimates for the year 2000 and projections for 2030. Diabetes Care 27:1047-1053

3. CDC (2011) National Diabetes Fact Sheet: national estimates and general information on diabetes and prediabetes in the United States. Atlanta, GA: US Department of Health and Human Services. http://www.cdc.gov/diabetes/pubs/pdf/ndfs_ 2011.pdf. Accessed 28 March 2013

4. Krolewski AS, Kosinski EJ, Warram JH, Leland OS, Busick EJ, Asmal AC, Rand LI, Christlieb AR, Bradley RF, Kahn CR (1987) Magnitude and determinants of coronary artery disease in juvenile-onset, insulin-dependent diabetes mellitus. Am J Cardiol 59:750-755

5. Grundy SM, Benjamin IJ, Burke GL, Chait A, Eckel RH, Howard BV, Mitch W, Smith SC Jr, Sowers JR (1999) Diabetes and cardiovascular disease: a statement for healthcare professionals from the American Heart Association. Circulation 100:1134-1146

6. Libby P, Nathan DM, Abraham K, Brunzell JD, Fradkin JE, Haffner SM, Hsueh W, Rewers M, Roberts BT, Savage PJ, Skarlatos S, Wassef M, Rabadan-Diehl C, National Heart, Lung, and Blood Institute, National Institute of Diabetes and Digestive and Kidney Diseases Working Group on Cardiovascular Complications of Type 1 Diabetes Mellitus (2005) Report of the National Heart, Lung, and Blood Institute-National Institute of Diabetes and Digestive and Kidney Diseases Working Group on Cardiovascular Complications of Type 1 Diabetes Mellitus. Circulation 111:3489-3493

7. Hage FG, Lusa L, Dondi M, Giubbini R, Iskandrian AE, IAEA Diabetes Investigators (2013) Exercise stress tests for detecting myocardial ischemia in asymptomatic patients with diabetes mellitus. Am J Cardiol 112:14-20

8. Kannel WB, McGee DL (1979) Diabetes and glucose tolerance as risk factors for cardiovascular disease: the Framingham study. Diabetes Care 2:120-126

9. Pyörälä K, Laakso M, Uusitupa M (1987) Diabetes and atherosclerosis: an epidemiologic view. Diabetes Metab Rev 3:463-524

10. Stamler J, Vaccaro O, Neaton JD, Wentworth D (1993) Diabetes, other risk factors, and 12-year cardiovascular mortality for men screened in the Multiple Risk Factor Intervention Trial. Diabetes Care 16:434-444

11. Haffner SM, Lehto S, Rönnemaa T, Pyörälä K, Laakso M (1998) Mortality from coronary heart disease in subjects with type 2 diabetes and in nondiabetic subjects with and without prior myocardial infarction. N Engl J Med 339:229-234

12. Grundy SM, Cleeman JI, Merz CN, Brewer HB Jr, Clark LT, Hunninghake DB, Pasternak RC, Smith SC Jr, Stone NJ, National Heart, Lung, and Blood Institute, American College of Cardiology Foundation, American Heart Association (2004) Implications of recent clinical trials for the National Cholesterol Education Program adult treatment panel III guidelines. Circulation 110:227-239

13. Huxley R, Barzi F, Woodward M (2006) Excess risk of fatal coronary heart disease associated with diabetes in men and women: meta-analysis of 37 prospective cohort studies. BMJ 332:73-78

14. Evans JM, Wang J, Morris AD (2002) Comparison of cardiovascular risk between patients with type 2 diabetes and those who had had a myocardial infarction: cross sectional and cohort studies. BMJ 324:939-942

15. Lee CD, Folsom AR, Pankow JS, Brancati FL, Atherosclerosis Risk in Communities (ARIC) Study Investigators (2004)
Cardiovascular events in diabetic and nondiabetic adults with or without history of myocardial infarction. Circulation 109:855-860

16. Howard BV, Best LG, Galloway JM, Howard WJ, Jones K, Lee ET, Ratner RE, Resnick HE, Devereux RB (2006) Coronary heart disease risk equivalence in diabetes depends on concomitant risk factors. Diabetes Care 29:391-397

17. Wong ND, Glovaci D, Wong K, Malik S, Franklin SS, Wygant G, Iloeje U (2012) Global cardiovascular disease risk assessment in United States adults with diabetes. Diab Vasc Dis Res 9:146-152

18. Bulugahapitiya U, Siyambalapitiya S, Sithole J, Idris I (2009) Is diabetes a coronary risk equivalent? Systematic review and meta-analysis. Diabet Med 26:142-148

19. Young LH, Wackers FJ, Chyun DA, Davey JA, Barrett EJ, Taillefer R, Heller GV, Iskandrian AE, Wittlin SD, Filipchuk N, Ratner RE, Inzucchi SE, DIAD Investigators (2009) Cardiac outcomes after screening for asymptomatic coronary artery disease in patients with type 2 diabetes: the DIAD study: a randomized controlled trial. JAMA 301:1547-1555

20. Saely CH, Aczel S, Koch L, Schmid F, Marte T, Huber K, Drexel H (2010) Diabetes as a coronary artery disease risk equivalent: before a change of paradigm? Eur J Cardiovasc Prev Rehabil 17:94-99

21. Emerging Risk Factors Collaboration, Sarwar N, Gao P, Seshasai SR, Gobin R, Kaptoge S, Di Angelantonio E, Ingelsson E, Lawlor DA, Selvin E, Stampfer M, Stehouwer CD, Lewington S, Pennells L, Thompson A, Sattar N, White IR, Ray KK, Danesh J (2010) Diabetes mellitus, fasting blood glucose concentration, and risk of vascular disease: a collaborative metaanalysis of 102 prospective studies. Lancet 375:2215-2222

22. Hu FB, Stampfer MJ, Haffner SM, Solomon CG, Willett WC, Manson JE (2002) Elevated risk of cardiovascular disease prior to clinical diagnosis of type 2 diabetes. Diabetes Care 25:1129-1134

23. Ehl NF, Kühne M, Brinkert M, Müller-Brand J, Zellweger MJ (2011) Diabetes reduces left ventricular ejection fractionirrespective of presence and extent of coronary artery disease. Eur J Endocrinol 165:945-951

24. Paillole C, Dahan M, Paycha F, Solal AC, Passa P, Gourgon R (1989) Prevalence and significance of left ventricular filling abnormalities determined by Doppler echocardiography in young type I (insulin-dependent) diabetic patients. Am J Cardiol 64:1010-1016

25. Zarich SW, Arbuckle BE, Cohen LR, Roberts M, Nesto RW (1988) Diastolic abnormalities in young asymptomatic diabetic patients assessed by pulsed Doppler echocardiography. J Am Coll Cardiol 12:114-120

26. Owan TE, Hodge DO, Herges RM, Jacobsen SJ, Roger VL, Redfield MM (2006) Trends in prevalence and outcome of heart failure with preserved ejection fraction. N Engl J Med 355:251-259

27. Daniels LB, Grady D, Mosca L, Collins P, Mitlak BH, AmewouAtisso MG, Wenger NK, Barrett-Connor E, Raloxifene Use for the Heart (RUTH) Trial Investigators (2013) Is diabetes mellitus a heart disease equivalent in women? Results from an international study of postmenopausal women in the Raloxifene Use for the Heart (RUTH) Trial. Circ Cardiovasc Qual Outcomes 6:164-170

28. Malik S, Budoff MJ, Katz R, Blumenthal RS, Bertoni AG, Nasir K, Szklo M, Barr RG, Wong ND (2011) Impact of subclinical atherosclerosis on cardiovascular disease events in individuals with metabolic syndrome and diabetes: the multi-ethnic study of atherosclerosis. Diabetes Care 34:2285-2290

29. Niccoli G, Giubilato S, Di Vito L, Leo A, Cosentino N, Pitocco D, Marco V, Ghirlanda G, Prati F, Crea F (2013) Severity of 
coronary atherosclerosis in patients with a first acute coronary event: a diabetes paradox. Eur Heart J 34:729-741

30. Janand-Delenne B, Savin B, Habib G, Bory M, Vague P, Lassmann-Vague V (1999) Silent myocardial ischemia in patients with diabetes: who to screen. Diabetes Care 22:1396-1400

31. Bruining $N$ (2013) The diabetes conundrum: despite increasing incidences of coronary disease in diabetic type II patients, their first cathlab presentation is later than expected: observations from an angiographic and optical coherence tomography study. Eur Heart J 34:715-718

32. Kim HW, Klem I, Shah DJ, Wu E, Meyers SN, Parker MA, Crowley AL, Bonow RO, Judd RM, Kim RJ (2009) Unrecognized non-Q-wave myocardial infarction: prevalence and prognostic significance in patients with suspected coronary disease. PLoS Med 6:e1000057

33. Scirica BM (2013) Prevalence, incidence, and implications of silent myocardial infarctions in patients with diabetes mellitus. Circulation 127:965-967

34. Davis TM, Coleman RL, Holman RR, UKPDS Group (2013) Prognostic significance of silent myocardial infarction in newly diagnosed type 2 diabetes mellitus: United Kingdom Prospective Diabetes Study (UKPDS) 79. Circulation 127:980-987

35. Chamnan P, Simmons RK, Sharp SJ, Griffin SJ, Wareham NJ (2009) Cardiovascular risk assessment scores for people with diabetes: a systematic review. Diabetologia 52:2001-2014

36. van Dieren S, Beulens JW, Kengne AP, Peelen LM, Rutten GE, Woodward M, van der Schouw YT, Moons KG (2012) Prediction models for the risk of cardiovascular disease in patients with type 2 diabetes: a systematic review. Heart 98:360-369

37. Kengne AP, Patel A, Marre M, Travert F, Lievre M, Zoungas S, Chalmers J, Colagiuri S, Grobbee DE, Hamet P, Heller S, Neal B, Woodward M, ADVANCE Collaborative Group (2011) Contemporary model for cardiovascular risk prediction in people with type 2 diabetes. Eur J Cardiovasc Prev Rehabil 18:393-398

38. Kothari V, Stevens RJ, Adler AI, Stratton IM, Manley SE, Neil HA, Holman RR (2002) UKPDS 60: risk of stroke in type 2 diabetes estimated by the UK Prospective Diabetes Study risk engine. Stroke 33:1776-1781

39. Stevens RJ, Kothari V, Adler AI, Stratton IM, United Kingdom Prospective Diabetes Study (UKPDS) Group (2001) The UKPDS risk engine: a model for the risk of coronary heart disease in Type II diabetes (UKPDS 56). Clin Sci (Lond) 101:671-679

40. Bansal S, Wackers FJ, Inzucchi SE, Chyun DA, Davey JA, Staib LH, Young LH, DIAD Study Investigators (2011) Five-year outcomes in high-risk participants in the Detection of Ischemia in Asymptomatic Diabetics (DIAD) study: a post hoc analysis. Diabetes Care 34:204-209

41. Acampa W, Petretta M, Evangelista L, Daniele S, Xhoxhi E, De Rimini ML, Cittanti C, Marranzano F, Spadafora M, Baldari S, Mansi L, Cuocolo A (2012) Myocardial perfusion imaging and risk classification for coronary heart disease in diabetic patients. The IDIS study: a prospective, multicentre trial. Eur J Nucl Med Mol Imaging 39:387-395

42. Saver BG, Hargraves JL, Mazor KM (2011) Are populationbased diabetes models useful for individual risk estimation? J Am Board Fam Med 24:399-406

43. Diamond GA, Kaul S, Shah PK (2007) Screen testing cardiovascular prevention in asymptomatic diabetic patients. J Am Coll Cardiol 49:1915-1917

44. Bax JJ, Bonow RO, Tschöpe D, Inzucchi SE, Barrett E, Global Dialogue Group for the Evaluation of Cardiovascular Risk in Patients With Diabetes (2006) The potential of myocardial perfusion scintigraphy for risk stratification of asymptomatic patients with type 2 diabetes. J Am Coll Cardiol 48:754-760
45. Miller TD, Redberg RF, Wackers FJ (2006) Screening asymptomatic diabetic patients for coronary artery disease: why not? J Am Coll Cardiol 48:761-764

46. Miller TD, Shaw LJ (2009) Risk stratification in diabetic patients: a continuing challenge. J Nucl Cardiol 16:486-489

47. Gibbons RJ, Balady GJ, Bricker JT, Chaitman BR, Fletcher GF, Froelicher VF, Mark DB, McCallister BD, Mooss AN, O'Reilly MG, Winters WL, Gibbons RJ, Antman EM, Alpert JS, Faxon DP, Fuster V, Gregoratos G, Hiratzka LF, Jacobs AK, Russell RO, Smith SC, American College of Cardiology/American Heart Association Task Force on Practice Guidelines, Committee to Update the 1997 Exercise Testing Guidelines, ACC/ AHA 2002 guideline update for exercise testing: summary article (2002) A report of the American College of Cardiology/ American Heart Association Task Force on Practice Guidelines (Committee to Update the 1997 Exercise Testing Guidelines). J Am Coll Cardiol 40:1531-1540

48. Hendel RC, Berman DS, Di Carli MF, Heidenreich PA, Henkin RE, Pellikka PA, Pohost GM, Williams KA, American College of Cardiology Foundation Appropriate Use Criteria Task Force, American Society of Nuclear Cardiology, American College of Radiology, American Heart Association, American Society of Echocardiology, Society of Cardiovascular Computed Tomography, Society for Cardiovascular Magnetic Resonance, Society of Nuclear Medicine (2009) ACCF/ASNC/ACR/AHA/ASE/ SCCT/SCMR/SNM 2009 Appropriate Use Criteria for Cardiac Radionuclide Imaging: A Report of the American College of Cardiology Foundation Appropriate Use Criteria Task Force, the American Society of Nuclear Cardiology, the American College of Radiology, the American Heart Association, the American Society of Echocardiography, the Society of Cardiovascular Computed Tomography, the Society for Cardiovascular Magnetic Resonance, and the Society of Nuclear Medicine. J Am Coll Cardiol 53:2201-2229

49. Patel MR, Spertus JA, Brindis RG, Hendel RC, Douglas PS, Peterson ED, Wolk MJ, Allen JM, Raskin IE, American College of Cardiology Foundation (2005) ACCF proposed method for evaluating the appropriateness of cardiovascular imaging. J Am Coll Cardiol 46:1606-1613

50. Greenland P, Alpert JS, Beller GA, Benjamin EJ, Budoff MJ, Fayad ZA, Foster E, Hlatky MA, Hodgson JM, Kushner FG, Lauer MS, Shaw LJ, Smith SC Jr, Taylor AJ, Weintraub WS, Wenger NK, Jacobs AK, American College of Cardiology Foundation/American Heart Association Task Force on Practice Guidelines (2010) 2010 ACCF/AHA guideline for assessment of cardiovascular risk in asymptomatic adults: a report of the American College of Cardiology Foundation/American Heart Association Task Force on Practice Guidelines. Circulation 122:e584-e636

51. Perrone-Filardi P, Achenbach S, Möhlenkamp S, Reiner Z, Sambuceti G, Schuijf JD, Van der Wall E, Kaufmann PA, Knuuti J, Schroeder S, Zellweger MJ (2011) Cardiac computed tomography and myocardial perfusion scintigraphy for risk stratification in asymptomatic individuals without known cardiovascular disease: a position statement of the Working Group on Nuclear Cardiology and Cardiac CT of the European Society of Cardiology. Eur Heart J 32:1986-1993

52. Mosca L, Benjamin EJ, Berra K, Bezanson JL, Dolor RJ, LloydJones DM, Newby LK, Piña IL, Roger VL, Shaw LJ, Zhao D, Beckie TM, Bushnell C, D'Armiento J, Kris-Etherton PM, Fang J, Ganiats TG, Gomes AS, Gracia CR, Haan CK, Jackson EA, Judelson DR, Kelepouris E, Lavie CJ, Moore A, Nussmeier NA, Ofili E, Oparil S, Ouyang P, Pinn VW, Sherif K, Smith SC Jr, Sopko G, Chandra-Strobos N, Urbina EM, Vaccarino V, Wenger NK (2011) Effectiveness-based guidelines for the prevention of cardiovascular disease in women-2011 update: a 
guideline from the American Heart Association. Circulation 123:1243-1462

53. American Diabetes Association (2013) Standards of medical care in diabetes-2013. Diabetes Care 36(Suppl 1):S11-S66

54. Di Carli MF, Hachamovitch R (2005) Should we screen for occult coronary artery disease among asymptomatic patients with diabetes? J Am Coll Cardiol 45:50-53

55. Beller GA (2007) Noninvasive screening for coronary atherosclerosis and silent ischemia in asymptomatic type 2 diabetic patients: is it appropriate and cost-effective? J Am Coll Cardiol 49:1918-1923

56. Danias PG, Ahlberg AW, Clark BA 3rd, Messineo F, Levine MG, McGill CC, Mann A, Clive J, Dougherty JE, Waters DD, Heller GV (1998) Combined assessment of myocardial perfusion and left ventricular function with exercise technetium-99 m sestamibi gated single-photon emission computed tomography can differentiate between ischemic and nonischemic dilated cardiomyopathy. Am J Cardiol 82:1253-1258

57. Spinelli L, Petretta M, Acampa W, He W, Petretta A, Bonaduce D, Cuocolo A (2003) Prognostic value of combined assessment of regional left ventricular function and myocardial perfusion by dobutamine and rest gated SPECT in patients with uncomplicated acute myocardial infarction. J Nucl Med 44:1023-1029

58. Bateman TM, Cullom SJ (2005) Attenuation correction singlephoton emission computed tomography myocardial perfusion imaging. Semin Nucl Med 35:37-51

59. Torremocha F, Hadjadj S, Carrié F, Rosenberg T, Herpin D, Maréchaud R (2001) Prediction of major coronary events by coronary risk profile and silent myocardial ischemia: prospective follow-up study of primary prevention in 72 diabetic patients. Diabetes Metab 27:49-57

60. Le Feuvre CL, Barthélémy O, Dubois-Laforgue D, Maunoury Ch, Mogenet A, Baubion N, Metzger JP, Timsit J (2005) Stress myocardial scintigraphy and dobutamine echocardiography in the detection of coronary disease in asymptomatic patients with type 2 diabetes. Diabetes Metab 31:135-142

61. Senior PA, Welsh RC, McDonald CG, Paty BW, Shapiro AM, Ryan EA (2005) Coronary artery disease is common in nonuremic, asymptomatic type 1 diabetic islet transplant candidates. Diabetes Care 28:866-872

62. Rajagopalan N, Miller TD, Hodge DO, Frye RL, Gibbons RJ (2005) Identifying high-risk asymptomatic diabetic patients who are candidates for screening stress single-photon emission computed tomography imaging. J Am Coll Cardiol 45:43-49

63. Zellweger MJ, Hachamovitch R, Kang X, Hayes SW, Friedman JD, Germano G, Pfisterer ME, Berman DS (2004) Prognostic relevance of symptoms versus objective evidence of coronary artery disease in diabetic patients. Eur Heart J 25:543-550

64. De Lorenzo A, Lima RS, Siqueira-Filho AG, Pantoja MR (2002) Prevalence and prognostic value of perfusion defects detected by stress technetium- $99 \mathrm{~m}$ sestamibi myocardial perfusion single-photon emission computed tomography in asymptomatic patients with diabetes mellitus and no known coronary artery disease. Am J Cardiol 90:827-832

65. Valensi P, Pariès J, Brulport-Cerisier V, Torremocha F, Sachs RN, Vanzetto G, Cosson E, Lormeau B, Attali JR, Maréchaud R, Estour B, Halimi S (2005) Predictive value of silent myocardial ischemia for cardiac events in diabetic patients: influence of age in a French multicenter study. Diabetes Care 28:2722-2727

66. Faglia E, Favales F, Calia P, Paleari F, Segalini G, Gamba PL, Rocca A, Musacchio N, Mastropasqua A, Testori G, Rampini P, Moratti F, Braga A, Morabito A, Milan Study on Atherosclerosis and Diabetes (Mi SAD) (2002) Cardiac events in 735 type 2 diabetic patients who underwent screening for unknown asymptomatic coronary heart disease: 5-year follow-up report from the Milan Study on Atherosclerosis and Diabetes (MiSAD). Diabetes Care 25:2032-2036
67. Inoguchi $\mathrm{T}$, Yamashita $\mathrm{T}$, Umeda F, Mihara H, Nakagaki O, Takada K, Kawano T, Murao H, Doi T, Nawata H (2000) High incidence of silent myocardial ischemia in elderly patients with non insulin-dependent diabetes mellitus. Diabetes Res Clin Pract 47:37-44

68. Cosson E, Paycha F, Paries J, Cattan S, Ramadan A, Meddah D, Attali JR, Valensi P (2004) Detecting silent coronary stenoses and stratifying cardiac risk in patients with diabetes: ECG stress test or exercise myocardial scintigraphy? Diabet Med 21:342-348

69. Sultan A, Piot C, Mariano-Goulart D, Daures JP, Comte F, Renard E, Avignon A (2006) Myocardial perfusion imaging and cardiac events in a cohort of asymptomatic patients with diabetes living in southern France. Diabet Med 23:410-418

70. Barthelemy O, Jacqueminet S, Rouzet F, Isnard R, Bouzamondo A, Le Guludec D, Grimaldi A, Metzger JP, Le Feuvre C (2008) Intensive cardiovascular risk factors therapy and prevalence of silent myocardial ischaemia in patients with type 2 diabetes. Arch Cardiovasc Dis 101:539-546

71. Acampa W, Petretta M, Daniele S, Del Prete G, Assante R, Zampella E, Cuocolo A (2013) Incremental prognostic value of stress myocardial perfusion imaging in asymptomatic diabetic patients. Atherosclerosis 227:307-312

72. Bourque JM, Patel CA, Ali MM, Perez M, Watson DD, Beller GA (2013) Prevalence and predictors of ischemia and outcomes in outpatients with diabetes mellitus referred for single-photon emission computed tomography myocardial perfusion imaging. Circ Cardiovase Imaging 6:466-477

73. de Araújo Gonçalves P, Garcia-Garcia HM, Carvalho MS, Dores H, Sousa PJ, Marques H, Ferreira A, Cardim N, Teles RC, Raposo L, Gabriel HM, Almeida M, Aleixo A, Carmo MM, Machado FP, Mendes M (2013) Diabetes as an independent predictor of high atherosclerotic burden assessed by coronary computed tomography angiography: the coronary artery disease equivalent revisited. Int J Cardiovasc Imaging 29:1105-1114

74. Petretta M, Daniele S, Acampa W, Imbriaco M, Pellegrino T, Messalli G, Xhoxhi E, Del Prete G, Nappi C, Accardo D, Angeloni F, Bonaduce D, Cuocolo A (2012) Prognostic value of coronary artery calcium score and coronary CT angiography in patients with intermediate risk of coronary artery disease. Int $\mathbf{J}$ Cardiovasc Imaging 28:1547-1556

75. Agarwal S, Morgan T, Herrington DM, Xu J, Cox AJ, Freedman BI, Carr JJ, Bowden DW (2011) Coronary calcium score and prediction of all-cause mortality in diabetes: the diabetes heart study. Diabetes Care 34:1219-1224

76. Agarwal S, Cox AJ, Herrington DM, Jorgensen NW, Xu J, Freedman BI, Carr JJ, Bowden DW (2013) Coronary calcium score predicts cardiovascular mortality in diabetes: diabetes heart study. Diabetes Care 36:972-977

77. Min JK, Dunning A, Lin FY, Achenbach S, Al-Mallah M, Budoff MJ, Cademartiri F, Callister TQ, Chang HJ, Cheng V, Chinnaiyan K, Chow BJ, Delago A, Hadamitzky M, Hausleiter J, Kaufmann P, Maffei E, Raff G, Shaw LJ, Villines T, Berman DS, CONFIRM Investigators (2011) Age- and sex-related differences in all-cause mortality risk based on coronary computed tomography angiography findings results from the International Multicenter CONFIRM (coronary CT angiography evaluation for clinical outcomes: an International Multicenter Registry) of 23,854 patients without known coronary artery disease. J Am Coll Cardiol 58:849-860

78. Chow BJ, Small G, Yam Y, Chen L, Achenbach S, Al-Mallah M, Berman DS, Budoff MJ, Cademartiri F, Callister TQ, Chang HJ, Cheng V, Chinnaiyan KM, Delago A, Dunning A, Hadamitzky M, Hausleiter J, Kaufmann P, Lin F, Maffei E, Raff GL, Shaw LJ, Villines TC, Min JK, CONFIRM Investigators (2011) Incremental prognostic value of cardiac computed tomography 
in coronary artery disease using CONFIRM: COroNary computed tomography angiography evaluation for clinical outcomes: an InteRnational Multicenter registry. Circ Cardiovasc Imaging 4:463-472

79. Papadopoulou SL, Brugaletta S, Garcia-Garcia HM, Rossi A, Girasis C, Dharampal AS, Neefjes LA, Ligthart J, Nieman K, Krestin GP, Serruys PW, de Feyter PJ (2012) Assessment of atherosclerotic plaques at coronary bifurcations with multidetector computed tomography angiography and intravascular ultrasound-virtual histology. Eur Heart J Cardiovasc Imaging 13:635-642

80. Saraste A, Knuuti J (2012) Novel CT-based imaging markers for high-risk coronary plaques. Eur Heart J Cardiovasc Imaging 13:633-634

81. Maehara A, Cristea E, Mintz GS, Lansky AJ, Dressler O, Biro S, Templin B, Virmani R, de Bruyne B, Serruys PW, Stone GW (2012) Definitions and methodology for the grayscale and radiofrequency intravascular ultrasound and coronary angiographic analyses. JACC Cardiovasc Imaging 5:S1-S9

82. Petretta M, Costanzo P, Perrone-Filardi P, Chiariello M (2010) Impact of gender in primary prevention of coronary heart disease with statin therapy: a meta-analysis. Int $\mathbf{J}$ Cardiol 138:25-31

83. Ray KK, Seshasai SR, Erqou S, Sever P, Jukema JW, Ford I, Sattar N (2010) Statins and all-cause mortality in high-risk primary prevention: a meta-analysis of 11 randomized controlled trials involving 65,229 participants. Arch Intern Med 170:1024-1031

84. Sarwar A, Shaw LJ, Shapiro MD, Blankstein R, Hoffmann U, Cury RC, Abbara S, Brady TJ, Budoff MJ, Blumenthal RS, Nasir K (2009) Diagnostic and prognostic value of absence of coronary artery calcification. JACC Cardiovasc Imaging 2:675-688

85. Anand DV, Lim E, Hopkins D, Corder R, Shaw LJ, Sharp P, Lipkin D, Lahiri A (2006) Risk stratification in uncomplicated type 2 diabetes: prospective evaluation of the combined use of coronary artery calcium imaging and selective myocardial perfusion scintigraphy. Eur Heart J 27:713-721

86. Vanzetto G, Halimi S, Hammoud T, Fagret D, Benhamou PY, Cordonnier D, Denis B, Machecourt J (1999) Prediction of cardiovascular events in clinically selected high-risk NIDDM patients. Prognostic value of exercise stress test and thallium201 single-photon emission computed tomography. Diabetes Care 22:19-26

87. Poulsen MK, Henriksen JE, Dahl J, Johansen A, Møller JE, Gerke O, Vach W, Haghfelt T, Beck-Nielsen H, Høilund-Carlsen PF (2009) Myocardial ischemia, carotid, and peripheral arterial disease and their interrelationship in type 2 diabetes patients. J Nucl Cardiol 16:878-887

88. Papaioannou GI, Kasapis C, Seip RL, Grey NJ, Katten D, Wackers FJ, Inzucchi SE, Engel S, Taylor A, Young LH, Chyun DA, Davey JA, Iskandrian AE, Ratner RE, Robinson EC, Carolan S, Heller GV (2006) Value of peripheral vascular endothelial function in the detection of relative myocardial ischemia in asymptomatic type 2 diabetic patients who underwent myocardial perfusion imaging. J Nucl Cardiol 13:362-368

89. Peix A, Cabrera LO, Heres F, Rodríguez L, Valdés A, Valiente J, García R, Licea M, Mendoza V, Gárciga F, Rodríguez Y, Carrillo R, Mena E, Fernández Y, Montero M, Dondi M (2011) Interrelationship between myocardial perfusion imaging, coronary calcium score, and endothelial function in asymptomatic diabetics and controls. J Nucl Cardiol 18:398-406

90. Greenland P, Bonow RO, Brundage BH, Budoff MJ, Eisenberg MJ, Grundy SM, Lauer MS, Post WS, Raggi P, Redberg RF, Rodgers GP, Shaw LJ, Taylor AJ, Weintraub WS, American College of Cardiology Foundation Clinical Expert Consensus
Task Force (ACCF/AHA Writing Committee to Update the 2000 Expert Consensus Document on Electron Beam Computed Tomography), Society of Atherosclerosis Imaging and Prevention, Society of Cardiovascular Computed Tomography (2007) ACCF/AHA 2007 clinical expert consensus document on coronary artery calcium scoring by computed tomography in global cardiovascular risk assessment and in evaluation of patients with chest pain: a report of the American College of Cardiology Foundation Clinical Expert Consensus Task Force (ACCF/AHA Writing Committee to Update the 2000 Expert Consensus Document on Electron Beam Computed Tomography) developed in collaboration with the Society of Atherosclerosis Imaging and Prevention and the Society of Cardiovascular Computed Tomography. J Am Coll Cardiol 49:378-402

91. Anand DV, Lim E, Lahiri A, Bax JJ (2006) The role of noninvasive imaging in the risk stratification of asymptomatic diabetic subjects. Eur Heart J 27:905-912

92. Rutter MK, McComb JM, Brady S, Marshall SM (1999) Silent myocardial ischemia and microalbuminuria in asymptomatic subjects with non-insulin-dependent diabetes mellitus. Am J Cardiol 83:27-31

93. Valensi P, Cosson E (2010) It is not yet the time to stop screening diabetic patients for silent myocardial ischaemia. Diabetes Metab 36:91-96

94. Kawasaki R, Cheung N, Islam FM, Klein R, Klein BE, Cotch MF, Sharrett AR, O'Leary D, Wong TY, Multi-Ethnic Study of Atherosclerosis (2011) Is diabetic retinopathy related to subclinical cardiovascular disease? Ophthalmology 118:860-865

95. Peix A (2013) Usefulness of nuclear cardiology techniques for silent ischemia detection in diabetics. MEDICC Rev 15:33-36

96. Hachamovitch R, Hayes S, Friedman JD, Cohen I, Shaw LJ, Germano G, Berman DS (2003) Determinants of risk and its temporal variation in patients with normal stress myocardial perfusion scans: what is the warranty period of a normal scan? J Am Coll Cardiol 41:1329-1340

97. Giri S, Shaw LJ, Murthy DR, Travin MI, Miller DD, Hachamovitch R, Borges-Neto S, Berman DS, Waters DD, Heller GV (2002) Impact of diabetes on the risk stratification using stress single-photon emission computed tomography myocardial perfusion imaging in patients with symptoms suggestive of coronary artery disease. Circulation 105:32-40

98. Iskander S, Iskandrian AE (1998) Risk assessment using singlephoton emission computed tomographic technetium- $99 \mathrm{~m}$ sestamibi imaging. J Am Coll Cardiol 32:57-62

99. Bateman TM (1997) Clinical relevance of a normal myocardial perfusion scintigraphic study. American Society of Nuclear Cardiology. J Nucl Cardiol 4(2 Pt 1):172-173

100. Min JK, Lin FY, Gidseg DS, Weinsaft JW, Berman DS, Shaw LJ, Rozanski A, Callister TQ (2010) Determinants of coronary calcium conversion among patients with a normal coronary calcium scan: what is the "warranty period" for remaining normal? J Am Coll Cardiol 55:1110-1117

101. Kiramijyan S, Ahmadi N, Isma'eel H, Flores F, Shaw LJ, Raggi P, Budoff MJ (2013) Impact of coronary artery calcium progression and statin therapy on clinical outcome in subjects with and without diabetes mellitus. Am J Cardiol 111:356-361

102. Leung DY, Ng AC (2010) Emerging clinical role of strain imaging in echocardiography. Heart Lung Circ 19:161-174

103. Ng AC, Delgado V, Bertini M, van der Meer RW, Rijzewijk LJ, Shanks M, Nucifora G, Smit JW, Diamant M, Romijn JA, de Roos A, Leung DY, Lamb HJ, Bax JJ (2009) Findings from left ventricular strain and strain rate imaging in asymptomatic patients with type 2 diabetes mellitus. Am J Cardiol 104:1398-1401

104. Hachamovitch R, Hayes SW, Friedman JD, Cohen I, Berman DS (2003) Comparison of the short-term survival benefit 
associated with revascularization compared with medical therapy in patients with no prior coronary artery disease undergoing stress myocardial perfusion single photon emission computed tomography. Circulation 107:2900-2907

105. Faglia E, Manuela M, Antonella Q, Michela G, Vincenzo C, Maurizio C, Roberto M, Alberto M (2005) Risk reduction of cardiac events by screening of unknown asymptomatic coronary artery disease in subjects with type 2 diabetes mellitus at high cardiovascular risk: an open-label randomized pilot study. Am Heart J 149:e1-e6

106. Vanzetto G, Boizel R, Halimi S, Ormezzano O, Belle L, Fagret D, Machecourt J (2007) Effects of a myocardial ischaemiaguided therapeutic program on survival and incidence of coronary events in asymptomatic patients with diabetes: the ARCADIA study. Diabetes Metab 33:459-465

107. Sorajja P, Chareonthaitawee P, Rajagopalan N, Miller TD, Frye RL, Hodge DO, Gibbons RJ (2005) Improved survival in asymptomatic diabetic patients with high-risk SPECT imaging treated with coronary artery bypass grafting. Circulation 112(9 Suppl):I311-I1316

108. Wackers FJ, Chyun DA, Young LH, Heller GV, Iskandrian AE, Davey JA, Barrett EJ, Taillefer R, Wittlin SD, Filipchuk N, Ratner RE, Inzucchi SE, Detection of Ischemia in
Asymptomatic Diabetics (DIAD) Investigators (2007) Resolution of asymptomatic myocardial ischemia in patients with type 2 diabetes in the Detection of Ischemia in Asymptomatic Diabetics (DIAD) study. Diabetes Care 30:2892-2898

109. Action to Control Cardiovascular Risk in Diabetes Study Group, Gerstein HC, Miller ME, Byington RP, Goff DC Jr, Bigger JT, Buse JB, Cushman WC, Genuth S, Ismail-Beigi F, Grimm RH Jr, Probstfield JL, Simons-Morton DG, Friedewald WT (2008) Effects of intensive glucose lowering in type 2 diabetes. N Engl J Med 358:2545-2559

110. BARI 2D Study Group, Frye RL, August P, Brooks MM, Hardison RM, Kelsey SF, MacGregor JM, Orchard TJ, Chaitman BR, Genuth SM, Goldberg SH, Hlatky MA, Jones TL, Molitch ME, Nesto RW, Sako EY, Sobel BE (2009) A randomized trial of therapies for type 2 diabetes and coronary artery disease. N Engl J Med 360:2503-2515

111. Brooks MM, Chaitman BR, Nesto RW, Hardison RM, Feit F, Gersh BJ, Krone RJ, Sako EY, Rogers WJ, Garber AJ, King SB 3rd, Davidson CJ, Ikeno F, Frye RL, BARI 2D Study Group (2012) Clinical and angiographic risk stratification and differential impact on treatment outcomes in the Bypass Angioplasty Revascularization Investigation 2 Diabetes (BARI 2D) trial. Circulation 126:2115-2124 